\title{
Educational Leadership in Greece during the Covid-19 Pandemic: Challenges and Prospects
}

\author{
Panagiotis Geropoulos (Corresponding author) \\ Philologist \\ Aristotle University of Thessaloniki, Greece \\ E-mail: pangerop@gmail.com
}

Kostis Tsioumis

Professor, School of Philosophy \& Education

Aristotle University of Thessaloniki, Greece

E-mail: ktsioumi@edlit.auth.gr

Received: October 5, 2021 Accepted: October 31, 2021 Published: November 15, 2021

doi:10.5296/ijld.v11i4.19085 URL: https://doi.org/10.5296/ijld.v11i4.19085

\begin{abstract}
The subject of this paper is a discussion on the treatment of the Covid-19 pandemic in the educational system of Greece. More specifically, it focuses on the policies and practices implemented by the principals of secondary education schools regarding the health crisis management in the school environment. The paper studies the actions concerning the administration of online teaching during the March-May 2020 period, as well as the reopening of schools in September after the first phase of the pandemic. Despite the difficulties, problems and various obstacles that the leaders met, it is expressed that certain positive elements can arise from the "experience" of the health crisis in education. At the same time, reference will be made to the policies and mandates of the Ministry of Education. So, the approach of the "leaders' practices" on a central and local level includes: 1) the organization and coordination of e-learning and 2) the challenges faced by secondary education principals during the conventional teaching period.
\end{abstract}

Keywords: Covid-19 pandemic, educational leadership, Greece, remote learning, secondary school principals, school system 


\section{Introduction}

The Covid-19 health crisis has had a significant impact on education systems around the world. Due to the measures taken to prevent the spread of the new coronavirus in the community, students were asked to leave the conventional teaching space. According to UNESCO estimates, more than 1.5 billion students worldwide have been forced to continue remote learning, using technology. (Sahlberg, 2020) Greece was one of the first countries in the world that on March 11, 2020, decided to suspend all educational activities at all levels. In this context and in a very short period of time, the principals of school units in Greece were called to, without being prepared in advance, organize the teaching using digital media. So this is an unexpected event that upset the educational status quo because there was no formal plan to manage the teaching of courses in a time of crisis. Expectedly, the Ministry of Education gave some general instructions and directions on how to implement it. In addition, it provided guidelines that governed many aspects of school life. The leaders, however, were the ones who took full responsibility for the adoption of the measures and the administration of the remote learning courses.

In addition, to the important work undertaken by educational leaders to carry out e-learning, in September 2020 they had to "settle" many issues for the smooth reopening of schools in combination with the risk of the virus still being an issue. According to Netolicky (2020), leaders in times of crisis must act promptly and with foresight. Initially, there was the thought of starting lessons early compared to previous years, specifically on 07-09-2020. Finally, due to the aggravated epidemiological situation, it was decided to call it off for a week.

The pandemic of Covid-19 has shaken not only the student community but also the duties and responsibilities of leaders. The crisis created by the pandemic has highlighted many problems in education that require special skills to solve them, such as communication, digital knowledge, empathy and interaction. (Alvarez et al. 2021) Let us gradually examine the attitudes and actions of the principals of Gymnasiums and Lyceums regarding these two sub-issues, along with the policies of the Ministry which in collaboration with the experts issued protocols of instructions on specific issues of personal protection.

\section{The e-Learning Endeavor and Educational Leadership}

The principals of all types of Gymnasiums and Lyceums in Greece had to form the appropriate framework in order for the students to remotely continue their learning. Complete abstention from the learning process would definitely be detrimental. According to Daniel, (2020) the coronavirus pandemic was the biggest challenge faced by national education systems. In the first phase of the pandemic, national policies concerned actions for students' access to the internet, the digitization of educational materials on platforms and issues of equal opportunities for all students regardless of geographical area and socio-economic status. (Anastasiadis, 2020)

The Ministry of Education in Greece has established WebEx as the main platform for the administration of e-learning. To enter WebEx they needed to register in the Panhellenic School Network. Prior to that it was necessary to collect the personal data of the students. 


\section{Macrothink}

The specific task was undertaken by the principals who were called to contact the students who had left the school. Therefore, they encountered additional problems as there was no direct and fast contact with them. For the provision of the provided services, according to the Ministry, the protection of personal data was ensured, which, however, was questioned. Additional obstacles were encountered in the cases of foreign students, who had not yet managed to sufficiently master the Greek language and communication was more difficult. The families of students could not assist the principals' efforts, especially if the working conditions of the parents did not allow them to engage in their children's activities. In the context of the research the principal of a school located in the region of central Macedonia states: "The success of the remote teaching is due to our colleagues, not to the Ministry. I encountered many problems and difficulties: every day they changed the orders they sent. Anything that happened - happened thanks to the honesty of the teachers". (Geropoulos et al.2021) So a heroic dimension is attributed to the amount of work undertaken by the teachers and the existing "forecasts" given by the central management.

Particular emphasis on this whole issue must be given to the lack of technological equipment on the part of both students and teaching staff. In this case, the cooperation of the central Ministry with the local educational leaders was poor. There was no concern for the identified needs of the students. Although principals submitted data on technological deficiencies, these gaps were not filled in a timely manner or with adequate resources. Municipalities did not equip the school units with the required electronic means either.

The competent bodies therefore bear more the form of Epimetheus than of Prometheus who provides in a timely and effective manner. Therefore, we can say that in practice it was not possible to implement e-learning. Thus, it can be said that participation in e-learning is determined by economic factors, since to a large extent the possession of a computer and internet access are what "define" the participation in the learning process. School principals "recruited" alternative means that acted as ancillary to the attendance of courses such as social media.

In Greece, perhaps, the lack of infrastructure became more apparent due to the previous ten-year economic crisis that left its mark on "investment" and financial support for education. As Sellars \& Imig, (2020) report internationally, many countries do not seem ready to act in a supportive way to mitigate the effects of the crisis on education. At this point, however, we need to mention that the Ministry of Education has reached an agreement with internet providers for the provision of free services.

In some cases, the principals, being empathetic and conscientious, tried to alleviate the technological inequalities by distributing printed material to the students who did not have the necessary means. In this context, Shahlberg (2020) finds that the pandemic has not created new inequalities but has exacerbated existing ones. Indeed, the economically and socially vulnerable groups were the ones most at risk of being left out of the educational procedures because their needs could not be adequately met. The principals, in order to provide the technological infrastructure, took the initiative, and requested private companies to provide donations to the educational units. As of December 2020, the Ministry of 
Education had announced the provision of vouchers to students to purchase computers or tablets. The program is called "digital care", but it has not been completed yet due to the bureaucracy that the Greek education system is facing to provide the required financial resources. According to the announcements of the Ministry of Education and Religions, in view of the new school year, the school units would be provided with 70,000 portable devices.

For the participation of children in the lessons there was no specific framework of instructions from the Ministry to the principals. That is, their participation in the course was not mandatory and was based on their "good volition". Thus, it was difficult for the teachers to control the participation in the lessons and to achieve the predefined didactic and pedagogical goals. Individual clarifications were given by the Institute of Educational Policy regarding the coverage of the course material. In addition, there was no single policy for synchronous or asynchronous teaching. In other words, there were ambiguities and the principals or teachers were given the opportunity to define the way of teaching according to the technological infrastructure they acquired. In terms of the level of skills of the teaching staff, this differed depending on their years of service, their age and their willingness to contribute in these difficult conditions. When a teacher was unable to meet the demands of remote learning, teachers or even leaders themselves, advocating the value of camaraderie, offered help, filling the gap.

The Ministry, in the beginning, did not officially conduct any form of training in the use of electronic media. Before the start of the new school year, school principals conducted training programs in the use of digital media.

The principals during the period of the health crisis worked long hours even after hours. The "key" to the success of remote learning seems to be the timely organization by school principals before the official instructions and directions of the Ministry. At the same time, the psychological support of teachers by the leaders with the rewards of individual actions created motivation and enthusiasm in the school community.

One of the positive outcomes of the crisis was the creation of a climate of cooperation within the educational community. Despite distance, all the members were in constant communication and were trying to compensate for the weak points that existed.

On May 18, 2020, after the first phase of the pandemic, it was decided to reopen the secondary schools with the gradual return of students to their activities. Priority was given to the students of the last grade of the Lyceum because conventional in-person teaching was crucial to the preparation for the Higher Education admission exams. Also, the special care given by the Ministry to reinstate the institution of remedial teaching was important. The end date of the courses of the academic year 2019-2020 for all types of Secondary schools was set at June 12, after a slight extension.

\section{School Life and Leadership Under the Threat of Covid-19}

In September 2020, after the first phase of the pandemic, there were expectations for a better school year with the physical presence of students. It was not desirable to continue the remote 
learning because it could work as a subsidiary and not on a permanent basis. The long duration of remote learning is tedious for both students and teachers. There is no direct interaction that conventional teaching offers with the benefits that result from it. The traditional mental rewards between teacher and student were undermined because of Covid-19(Hargreaves \& Fullan, 2020). The members of the educational community therefore had to "control" the emotional state of the students. Many of them were emotionally charged by the stress of not getting sick or by the loss of a loved one. (Pollock, 2020) The truth is that the first period of the pandemic provided "experience" to members of the educational and school community. Particularly important for the successful response to the crisis during the period of operation of the school units is the use of different leadership attitudes towards the members of the educational community depending on the existing conditions.

At the level of the central directorate, the Ministries of Education and Health, in collaboration with the competent health scientists, issued instructions regarding the observance of the necessary social distancing and hygiene rules. They provided information on the daily practices of the educational community. Students and teachers during their stay in the school unit had to use a protective mask in all indoor areas except during meal times. In addition, according to the Ministry, the use of a mask was mandatory in the means of transportation of students and outdoors, but only in cases where congestion was observed. For this reason, the principals were instructed to assign different break times to each student group. Special exemption provisions have been established for students with special educational needs or other conditions. Health protocols have set strict rules and new challenges for the school community, such as the reduction of students per class due to the lack of infrastructure. (Tria, 2020)

The Greek government in cooperation with local administration provided free masks to all students and teachers. The guidelines for the principals were that people who would come to the school without a mask would not be accepted and all the necessary pedagogical measures would be applied. Therefore, they would be left out of the educational process. In the implementation of this measure, the leaders faced ethical dilemmas because a solution had to be found for the students who inadvertently forgot the protective means and the strict instructions of the experts. Thus, some leaders made sure to procure additional disposable masks and to bear the financial costs themselves. The majority of the executives faithfully followed the orders given to them because as civil servants they had to follow the orders given by the central directorate of the Ministry.

The use of a mask was mandatory for all students and teachers throughout the lessons. The principals, as the heads of the educational units, as well as the other teachers, sought to be models of good behavior by applying the instructions proposed by the experts. However, there was a possibility that with its prolonged use, children would experience anxiety or fear. In this case, too, the intervention of the leaders was crucial, as they tried to provide psychological support to the students through discussion. The Ministry gave advice on the psychological information, empowerment and unloading of adolescents. For the best encouragement and support, phone communication with the special team of scientists of the National Public Health Organization (NPHO) was provided. Therefore, the role of principals 
is multifaceted. To a large extent, their actions determine the effectiveness and efficiency of students (Brauckmann \& Pashiardis, 2020). The conventional operation of the schools enabled the students to share their thoughts and reflections, which of course could not be replaced by the cold computer screen.

During the pandemic, school celebrations and student competitions were planned with the necessary precautionary measures. At the same time, all the educational visits, the school championships and the sessions that took place in the local school units were postponed. In all educational activities the Ministry gave to the principals the instruction of setting up small and stable cooperation groups in order to prevent the spread of the disease. For example, in the case of laboratories and computer classes there was the instruction to clean materials and equipment after use. Regarding extracurricular activities, students were advised to abstain from them. Certainly, there was a transfer of power and responsibility from the central management to the educational leaders regarding these measures. The principals were in charge of the task of informing the students in various ways such as video presentations and instructions for the proper use of the mask through information posters. Covid-19 created problems in students' internships as experts banned them from being conducted in school units. No principal could accept out-of-school people during this period.

During the crisis, their duties and responsibilities increased significantly. One reason is that the education system in Greece is highly bureaucratic and centralized. (Pasiardis, 2014, p.45) As the principals point out, many activities need the approval of the Ministry. This requires additional work with the handling of electronic and regular mail. Thus, the scope for autonomy and flexibility is limited. For this reason, the directors did not want their actions to be outside the framework, especially in matters of health. After all, most of them followed the laws faithfully. However, at this point we need to note that the Directors of Secondary Education as civil servants act more like managers, "handlers of cases" designated by the competent Ministry. Regarding the strict nature of the legal framework and the health crisis, a middle school principal reports in a discussion related on spreading Coronavirus: "For instance, I see that a child is struggling, they are drowning with the mask, I will talk to them, I can also call the family. I will help them but beyond that the legal framework is very suffocating. The principal, being a civil servant, must follow the laws. There is no possibility of deviation because this issue is very sensitive ". (Geropoulos et al., 2021) But in times of crisis like the Covid-19 pandemic, the leadership is imperative for more effective operation. That is, the inspiration and mobilization of the subordinates is needed to achieve the goals of the educational organization.

Our assessment is that a new learning environment is emerging in the Greek educational system. Educational policy makers recognize the need to solve problems at the school level and to create leadership training programs based on autonomy and accountability (Brauckmann et al., 2020). Thus, Covid-19 provides the opportunity to review the existing perception that exists in the management system of education. As the experience of the pandemic has shown, educational leaders are the ones who know best concerning the needs of the school unit. 


\section{Macrothink}

The health crisis that broke out in February 2020 and continues to plague educational institutions today has affected almost all aspects of school life and administration. The influence it exerted on the goals of the educational unit is considered important. In particular, the principals during the period of the health crisis could not set high goals and visions because the lessons were done despite many obstacles. The planning of the school administration, for example, was revised as it was difficult for students and teachers to keep to the schedule. Thus, the learning outcomes during the distance learning but also during the operation period of the school units are expected to be significantly reduced. The cooperation between the principal and the rest of the teaching staff during the pandemic period was complicated because the situation was unprecedented. Human resource management was one of the challenges faced by managers during the Covid-19 era. Teachers had their own perceptions of how to deal with the crisis and had to be convinced by leaders of the need to take action.

After the first phase of the suspension of the operation of the school units, the principals developed plans and exercise scenarios for the management of coronavirus cases in the school community. It was one of the instructions of the Ministry which the directors had to implement. In this context, guidelines were given for the absences of students and teachers with the obligation to present a medical certificate. Special mention was made of students living in vulnerable groups. For the cases where it was decided to suspend the operation of the school unit or even of an individual department, the option of synchronous or asynchronous remote learning was provided. The digital platforms were ready to use with the free provision of services by Cisco to the Greek government. The control by the principal regarding the reason for the absence of students and teachers is considered particularly important because he was the one responsible for the sample control by the services of National Public Health Organization (NPHO) in instances of increased Covid cases. educational leaders were required to inform their superiors to decide whether to suspend the in-person learning process.

At the same time, educational leaders needed to provide small departments with a maximum of 17 students per class. But again there was no clear instruction on how this would be done. Furthermore, the building and logistical infrastructure of schools in Greece are not sufficient to meet the educational needs. Therefore, the executives had to somehow find a solution between the large number of students and the limited space. It was one of the most pressing issues facing educational leaders. In some schools, students mobilized to claim smaller teaching groups.

\section{Conclusions}

The educational leadership in Greece, as in other countries during the pandemic, was faced with many problems for which it had not previously drawn up response plans. It was an unexpected event that demonstrated the pathogenesis of the educational administration.

The Covid-19 health crisis overturned existing leadership attitudes and practices. The directors "interpreted" in a special way the vague in many cases instructions of the Ministry. The fact that the principals of Secondary education in Greece come from different fields and 
hold different specialties played an important role in this. In many cases, educational leaders have been unaware of how to deal with the crisis as they are not trained in healthcare. Thus, the cooperation with the medical science and the competent bodies was decisive.

In addition, there was no single line from all executives for the implementation of e-learning. The success or failure of remote learning largely depends on the presence or absence of technological equipment in the home environment. Therefore, the family "profile" is the one that played an important role in the learning process during the pandemic. However, the personal actions and empathy of the principals were important in mitigating the effects of the crisis on educational practice. The passion and willingness they showed "filled" the gap of the state which in the end showed slow reflexes. It is noteworthy that the leaders diligently tried to reduce social inequalities in educational practice. In addition, the executives after the first period of the crisis were better prepared for the possibility of resumption of educational activity. Thus, the record of the educational process in the period of the pandemic is rather positive if we take into account the infrastructure and financial condition of the school units, the knowledge and skills of the teaching staff as well as the fear that existed in the face of the unknown.

Apart from the negative consequences that the crisis has brought upon the entire educational community, we must consider the benefits that may result from it in the future. Schools are given the opportunity to change the traditional way of learning with the widespread use of technology and distance education (Zhao, 2020). In Greece, the educational leadership, both centrally and locally, needs to redefine teaching methods, give priority to the technological upgrade of school units and prepare plans for dealing with future risks. The shielding of vulnerable groups, which are more exposed to "risk", is necessary based on the new conditions that are now created in education.

\section{References}

Álvarez-Arregui, E., Pérez-Navío, E., González-Fernández, R., \& Rodríguez-Martín, A. (2021). Pedagogical Leaders and the Teaching-Learning Processes in COVID-19 Times. International Journal of Environmental Research and Public Health, 18(15), 7731. https://doi.org/10.3390/ijerph18157731

Anastasiadis, P. (2020). Distance learning in the era of Covid-19, focusing on the Greek Educational System. The journal for Open and Distance Educational Technology. https://doi.org/10.12681/jode.25506

Brauckmann, S., \& Pashiardis, P. (2020). Entrepreneurial leadership in schools: linking creativity with accountability. International Journal of Leadership in Education, 00 (00), 1-15. https://doi.org/10.1080/13603124.2020.1804624

Brauckmann, S., Pashiardis, P., \& lestrlestig, H. (2020). Bringing context and educational leadership together: fostering the professional development of school principals. Professional Development in Education, 00 (00), 1-12. https://doi.org/10.1080/19415257.2020.1747105

Daniel, S. J. (2020). Education and the COVID-19 pandemic. Prospects, 49(1-2), 91-96. 


\section{Macrothink}

https://doi.org/10.1007/s11125-020-09464-3

Geropoulos, P., Tsioumis K., \& Loufopoulos, I. (2021). Pedagogical leadership practices for the management of Covid-19 pandemic in the Greek school system. Journal of Studies in Education, 11(3). 59. https://doi.org/10.5296/jse.v11i3.18726

Hargreaves, A., \& Fullan, M. (2020). Professional capital after the pandemic: revisiting and revising classic understandings of teachers 'work. Journal of Professional Capital and Community, 5(3-4), 327-336. https://doi.org/10.1108/JPCC-06-2020-0039

Netolicky, D. M. (2020). School leadership during a pandemic: navigating tensions. Journal of Professional Capital and Community, 5(3-4), 391-395. https://doi.org/10.1108/JPCC-05-2020-0017

Pashiardis, P. (2014). Educational Leadership: From the period of favorable indifference to the modern era. Athens: Metaichmio.

Pollock, K. (2020). School Leaders' Work During the COVID-19 Pandemic: A Two-Pronged Approach. International Studies in Education, 48(3), 38-44.

Sahlberg, P. (2020). Will the pandemic change schools? Journal of Professional Capital and Community, 5(3-4), 359-365. https://doi.org/10.1108/JPCC-05-2020-0026

Sellars, M., \& Imig, S. (2020). The real cost of neoliberalism for educators and students. International Journal of Leadership in Education, 00(00), 1-13. https://doi.org/10.1080/13603124.2020.1823488

Tria, J. Z. (2020). The COVID-19 Pandemic through the Lens of Education in the Philippines: The New Normal. International Journal of Pedagogical Development and Lifelong Learning, 1(1), ep2001. https://doi.org/10.30935/ijpdll/8311

Zhao, Y. (2020). COVID-19 as a catalyst for educational change. Prospects, 49(1-2), 29-33. https://doi.org/10.1007/s11125-020-09477-y

\section{Copyright Disclaimer}

Copyright for this article is retained by the author(s), with first publication rights granted to the journal.

This is an open-access article distributed under the terms and conditions of the Creative Commons Attribution license (http://creativecommons.org/licenses/by/4.0/). 